\title{
Vitreous Humor
}

National Cancer Institute

\section{Source}

National Cancer Institute. Vitreous Humor. NCI Thesaurus. Code C13323.

The clear colorless transparent jelly that fills the posterior chamber of the eyeball. 